\title{
ELEVATION OF CONDENSED TANNINS IN THE LEAVES OF Ta-M YB14-1 WHITE CLOVER (Trifolium repens L.) OUTCROSSED WITH HIGH ANTHOCYANIN LINES
}

Marissa B. Roldan,*, Greig Cousins, Karl Fraser, Kerry R. Hancock, Vern Collette, Jerome Demmer, Derek R. Woodfield, John

R. Caradus, Chris Jones and Christine R. Voisey*

Journal of Agricultural and Food Chemistry 


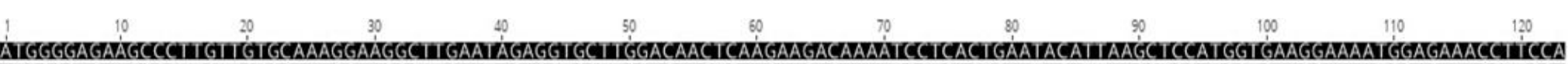

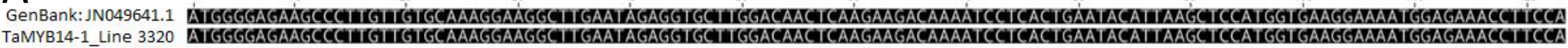

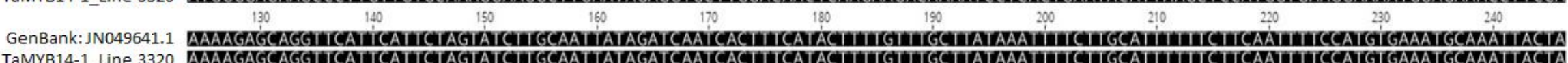

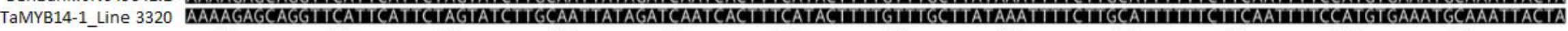

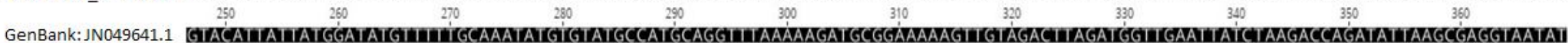
TaMYB14-1_Line 3320 GTACATIATIATGGATATGIIITIGCAAATATGTGTATGCCATGCAGGIITAAAAAGATGCGGAAAAAGIIGIAGACITAGATGGIIGAATIATCTAAGACCAGATATITAGGGAGGTAATAI

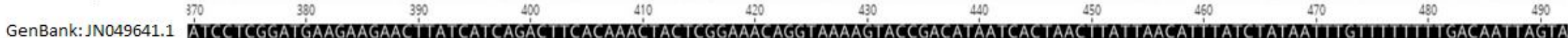
TaMYB14-1_Line 3320 ATCCICGGATGAAGAAGAACTIATCATCAGACIICACAAACTACTCGGAAACAGGTAAAAGTACCGACATAATCACTAACITAT TAACATIITATCTATAAIIIGIIIIIIIIIGACAATIAGTA GenBank: JN049641.1

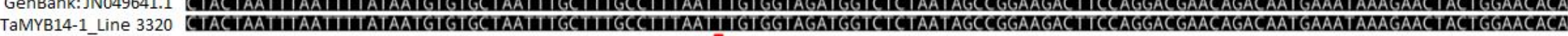

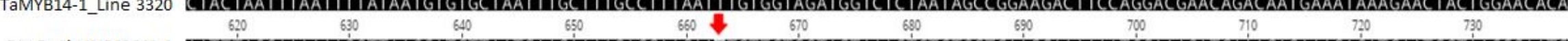

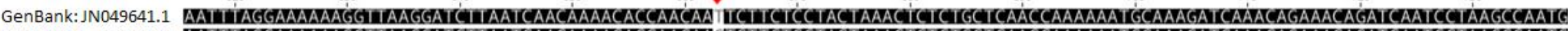

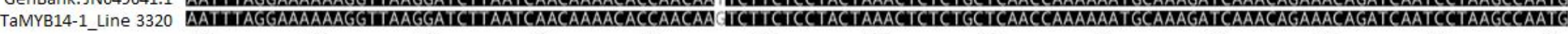

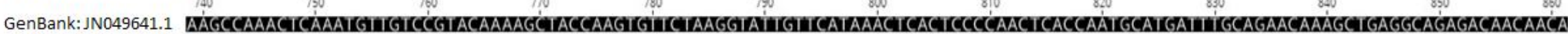

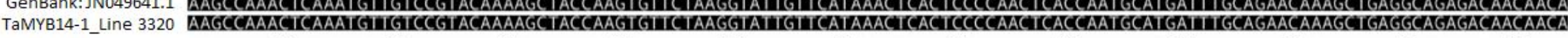

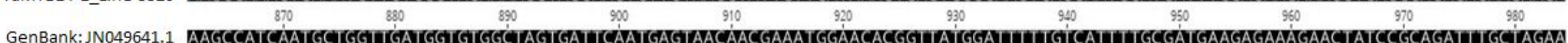

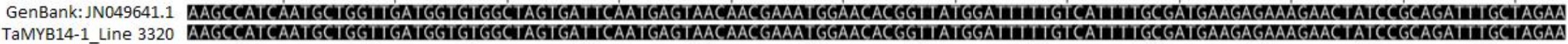
TaMYB14-1_Line 3320 A.

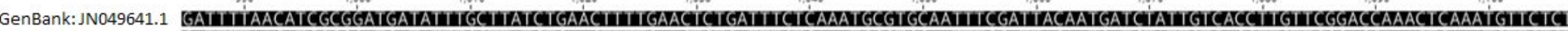

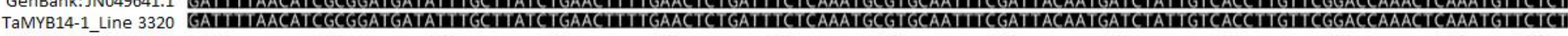

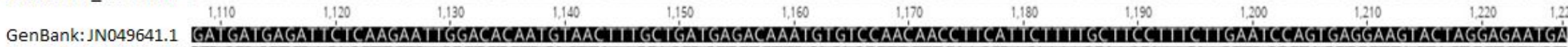

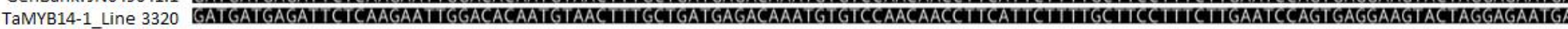

B

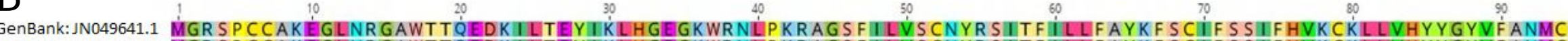

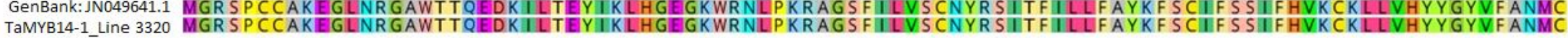

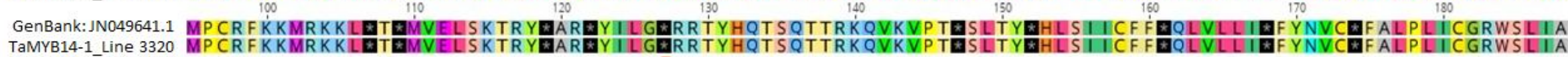

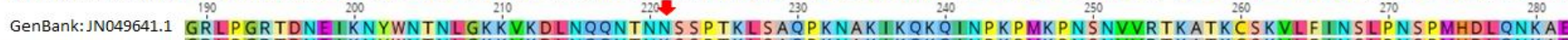
TaMYB14-1_Line 3320 GRLPGRTDNEIKNYWNTNLGK KVKDLNQQNTNKS SPTKLSAQP KNAKIKQKQINPKPMKPNSNVVRTKATKC SKVLFIINSLPNSPMHDLQNKAE

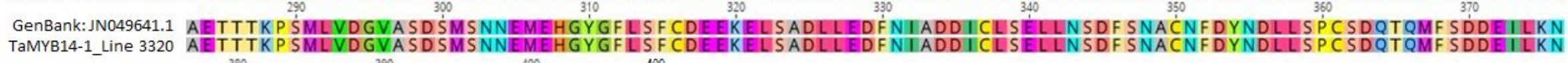

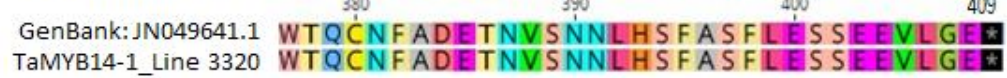

Supplemental Figure S1. Alignment of nucleotide (A) and translated amino acid (B) sequences of Ta-M YB14-1 previously submitted to NCBI (GenBank JN049641.1), and the Ta-M YB14-1 sequence inserted in the transgenic white clover plant T0(3320). The change in base pair T663G and translated amino acid N221K is indicated by the red arrow. 
A

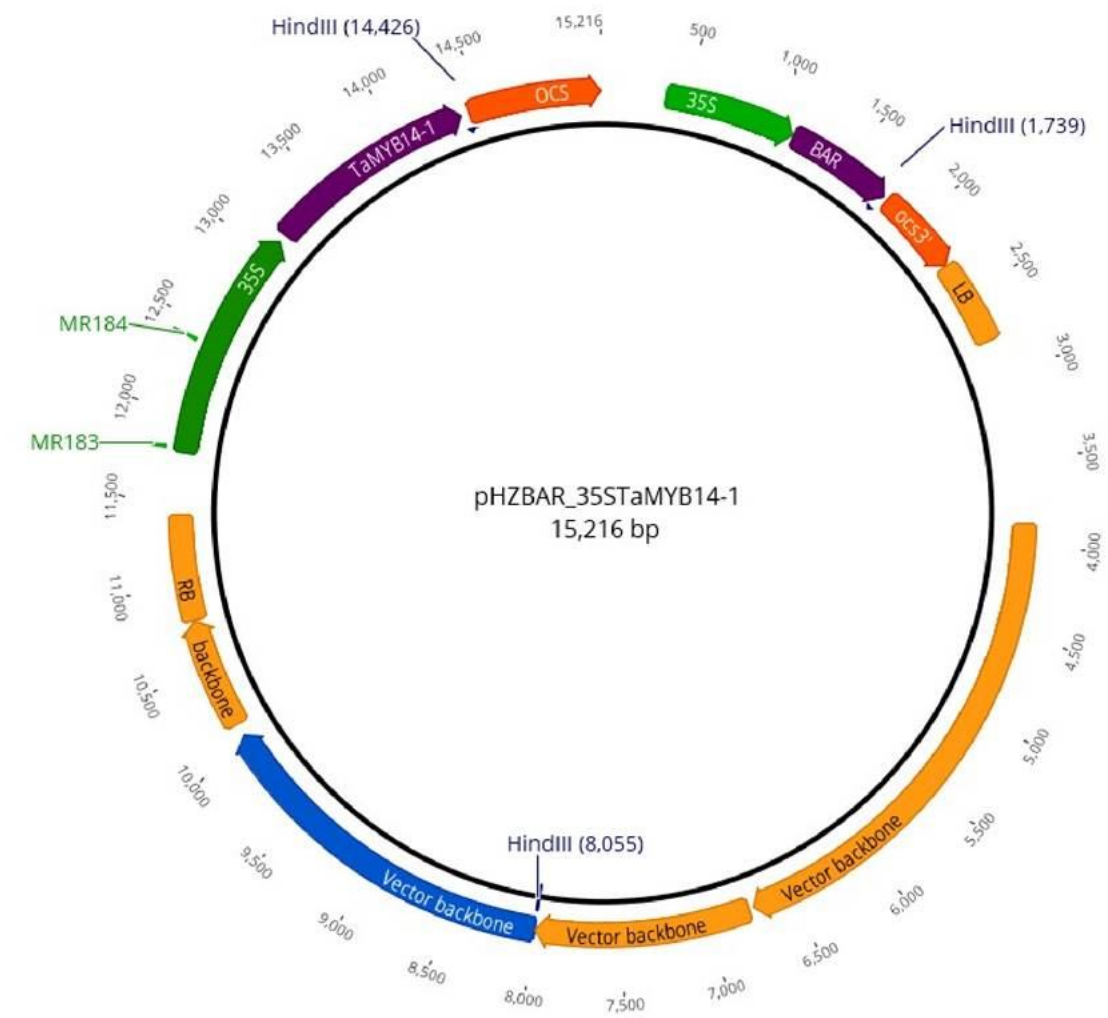

B Size

$(\mathrm{Kb})$

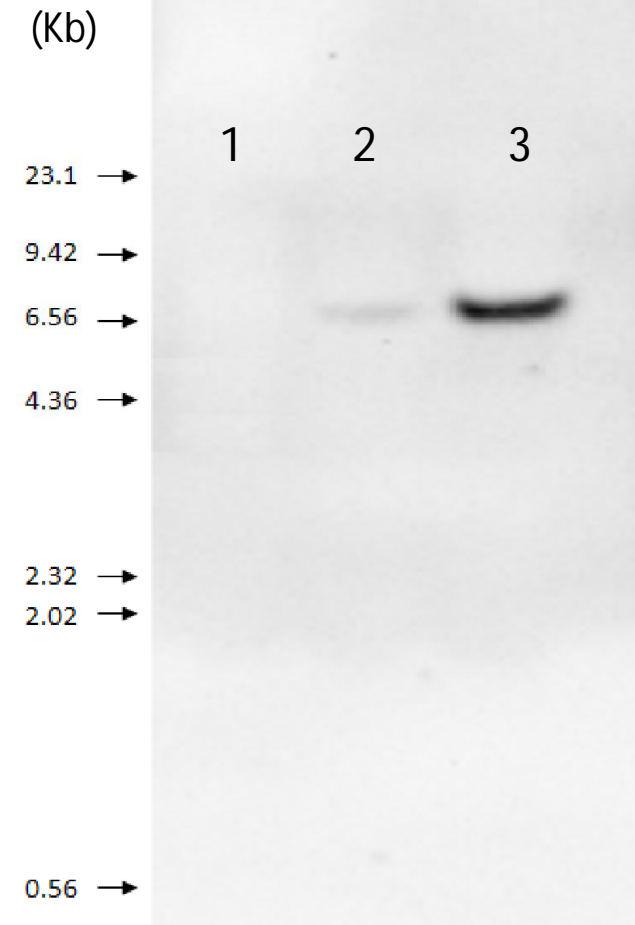

Supplemental Figure S2. A. Schematic of TI plasmid pHZBar_35STaMYB14-1 ${ }^{1}$ used to transform white clover. The position of the HindlII restriction sites, plus the binding sites of PCR primers (M R183 and M R184) used to amplify the DNA (627 bp) for probe synthesis, are shown. See Supplemental Table S1 for primer sequences. RB \& LB: right and left T-DNA borders; BAR: phosphinothricin resistance gene; OCS: octopine synthase terminator, 35S: cauliflower mosaic virus $35 \mathrm{~S}$ promoter. The $35 \mathrm{~S}$ promoter upstream of the BAR gene is truncated and does not contain a probe binding site. B. Southern blot hybridization to determine gene copy number in primary transgenic white clover plant T0(3320). Genomic DNA $(10 \mu \mathrm{g})$ was digested with Hindlll, blotted onto positively-charged nylon membrane and hybridized with a digoxygenin (DIG)-labelled probe synthesized using M R183 \& M R184 primers. 1) Untransformed white clover DNA. 2) White clover primary transgenic plant T0(3320). 3) HindllI-digested DNA of plasmid pHZBar_35STaM YB14-1. The DNA size standard was the M olecular Weight M arker II, Digoxigenin-labelled (Sigma-Aldrich, New Zealand).

${ }^{1}$ Hancock, K. R. et al., 2012. Expression of the R2R3-M YB transcription factor TaM YB14 from Trifolium arvense activates proanthocyanidin biosynthesis in the legumes Trifolium repens and M edicago sativa. Plant physiology 159, 1204-1220. 


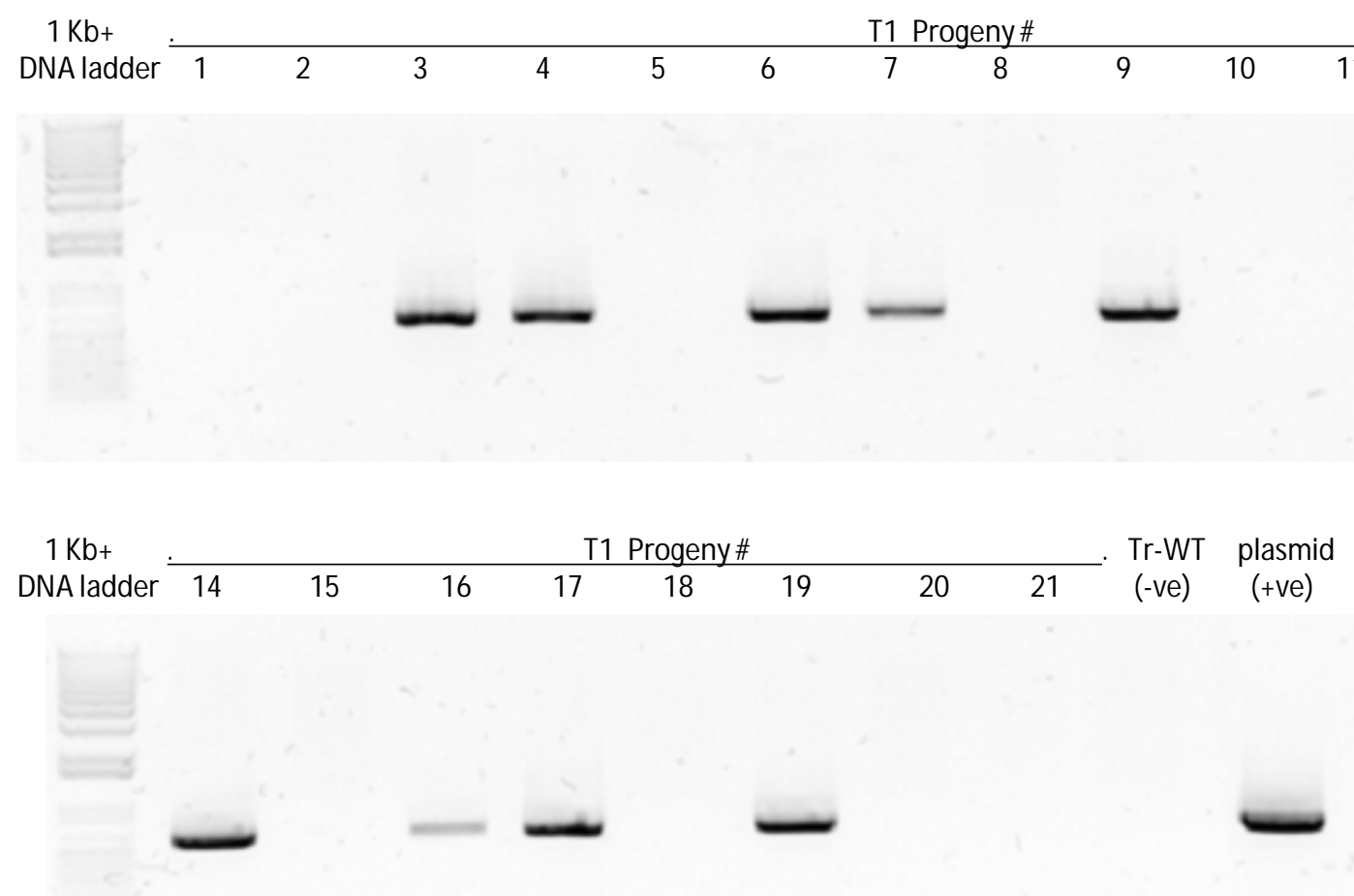

Supplemental Figure S3. Representative PCR analysis of DNA from $21 \mathrm{~T} 1$ progeny from a cross between TO(3320) and WT-LAC1 showing approximately 50\% are positive for TaM YB14-1. Tr-WT is DNA from wild type white clover. The positive control is plasmid pHZBar_35STaM YB14-1. The primers used were M R183 and M R184 (see Supplemental Table S1). The 1Kb+DNA ladder is from Life Technologies, California, USA). 

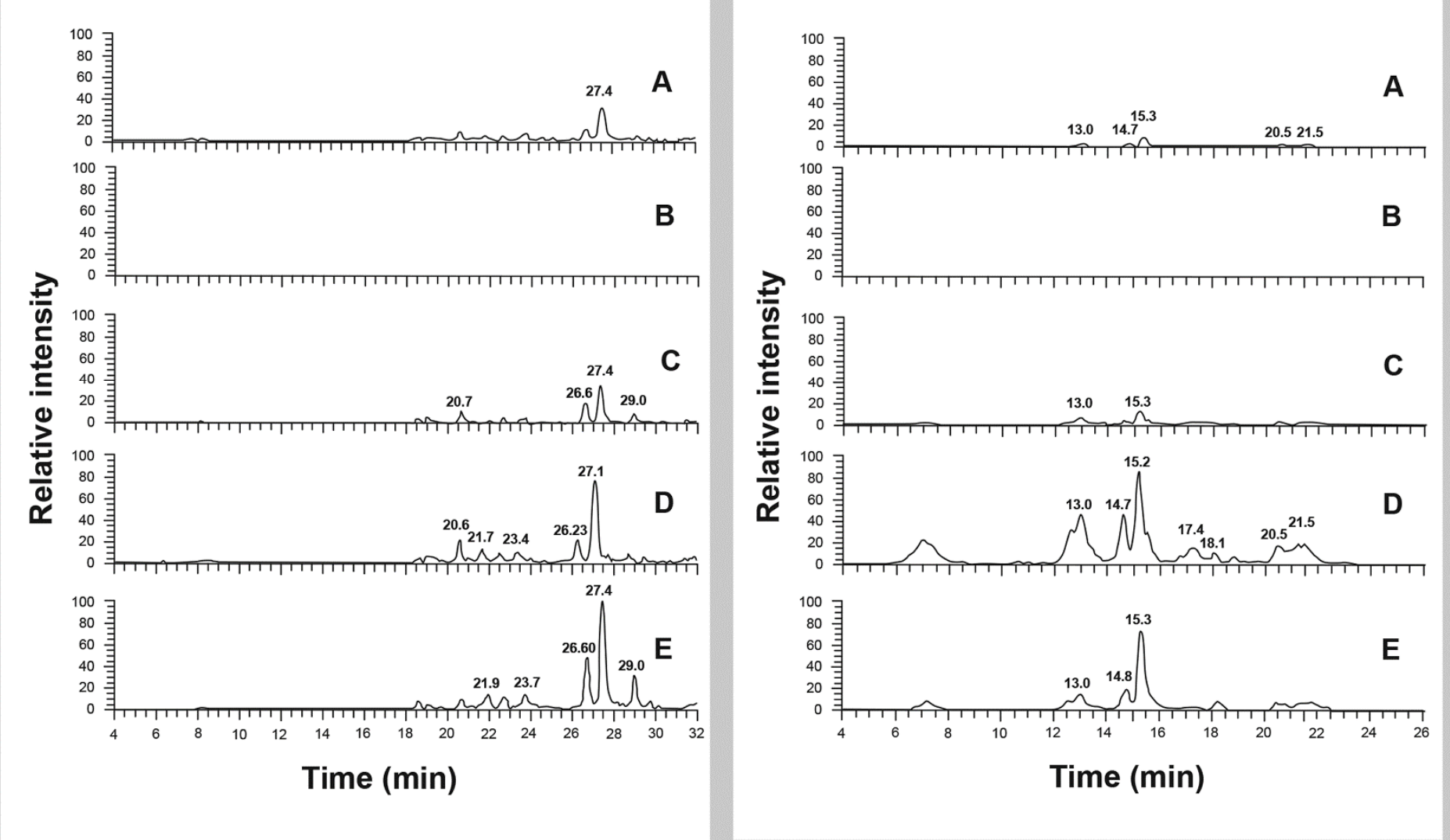

Supplemental Figure S4. Extracted ion chromatograms of summed M S2 product ions (in bold below) from the $[\mathrm{M}+\mathrm{H}]$ parent ions for i) $867.3 \rightarrow \mathbf{5 7 7}+\mathbf{5 7 9} \mathrm{m} / \mathrm{z}$ transition of procyanidin (PC) trimer peaks demonstrating the presence of PC trimers in (A) the TO(3320) plant and (B) a null segregant from pT1-HAC2 (negative control), plus representatives of (C) a pT1-HAC1, (D) a pT2-HACa and (E) a pBC2-HACla plant (see Supplemental Table S3 for plant details). The Y-axis is fixed at the same level for all leaf extracts, and ii) 915.3 $\rightarrow \mathbf{6 0 9}+\mathbf{6 1 1} \mathrm{m} / \mathrm{z}$ transition of prodelphinidin (PD) trimer peaks demonstrating the presence of PD trimers across the same samples $(\mathrm{A}-\mathrm{E})$. 
A

\begin{tabular}{|c|c|c|c|c|}
\hline $\begin{array}{l}\text { Primer } \\
\text { Name }\end{array}$ & Orientation & Gene/ Description & Function & Primer sequences \\
\hline M R175 & $S$ & TaM YB14-1 & sequencing & ATGGGGAGAAGCCCTTGTT \\
\hline M R119 & $\mathrm{S}$ & TaM YB14-1 & sequencing & GTACCGACATAATCACTAAC \\
\hline M R118 & AS & TaM Yb14-1 & sequencing & GCTATTAGAGACCATCTAC \\
\hline M R121 & AS & TaM YB14-1 & sequencing & GAGAGTITAGTAGGAGAAG \\
\hline M R120 & $\mathrm{S}$ & TaM YB14-1 & sequencing & ССАААСТCAААТG TTСТСТG \\
\hline M R178 & AS & TaM Yb14-1 & sequencing & GCCCTITCATTCTCCTAGTACT \\
\hline M R122 & AS & TaM YB14-1 & sequencing & CCAAGCACCTCTATTCAAGCC \\
\hline M R183 & $S$ & CaM V35S promoter & probe synthesis & СССАCAAAAATCTGAGCTTA \\
\hline M R184 & AS & CaM V35S promoter & probe synthesis & TGCATCTITAACCTTCTTGG \\
\hline M R188 & $S$ & OCS $3^{\prime}$ & sequencing & TATGATAGAGCGCCACAATA \\
\hline M R190 & AS & Left border & sequencing & GTATATCGTGCGAAAAAGGA \\
\hline M R201 & AS & CaM V35S pro 5' & sequencing & CTCAGATIITGTGGGATTGGA \\
\hline MR201S & $\mathrm{S}$ & pHZBAR-RB & sequencing & GGAGAATTAAGGGAGTCA \\
\hline
\end{tabular}

B

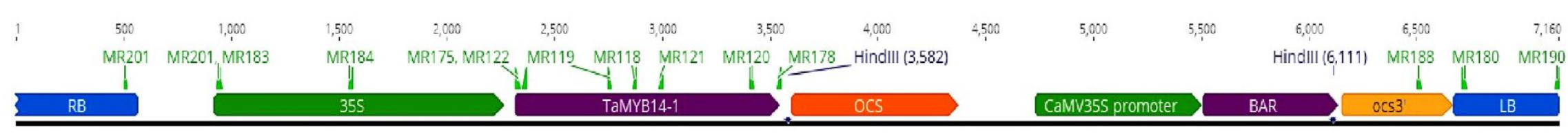

Supplemental Table S1. A.)Primer sequences used in this study, and their function. B) Position of the primer in the T-DNA of transformation vector pHZBar_35STaM YB14-1. S: sense strand; AS: anti-sense strand. 


\begin{tabular}{|c|c|c|c|c|}
\hline $\begin{array}{c}\text { T1 progeny } \\
\text { group }\end{array}$ & $\begin{array}{c}\text { Number of CT +ve } \\
\text { progeny analysed }\end{array}$ & $\begin{array}{c}\mathrm{CT}(\% \mathrm{DM}) \\
\text { Progeny mean }\end{array}$ & $\begin{array}{c}\mathrm{CT}(\% \mathrm{DM}) \text { in } \\
\text { highest plant }\end{array}$ & $\begin{array}{c}\mathrm{CT}(\% \mathrm{DM}) \text { in second } \\
\text { highest plant }\end{array}$ \\
\hline PT1-HAC1 & 26 & 0.78 & 1.71 & 1.52 \\
\hline PT1-HAC2 & 24 & 0.74 & 1.42 & 1.26 \\
\hline PT1-LAC1 & 9 & 0.50 & 0.91 & 0.85 \\
\hline PT1-LAC2 & 9 & 0.43 & 0.86 & 0.67 \\
\hline
\end{tabular}

\section{B}

\begin{tabular}{|c|c|c|c|c|}
\hline $\begin{array}{c}\mathrm{BC} 2 \& \mathrm{T2} \\
\text { progeny groups }\end{array}$ & $\begin{array}{c}\text { Number of CT +ve } \\
\text { progeny analysed }\end{array}$ & $\begin{array}{c}\mathrm{CT}(\% \mathrm{DM}) \\
\text { Progeny mean }\end{array}$ & $\begin{array}{c}\mathrm{CT}(\% \mathrm{DM}) \text { in } \\
\text { highest plant }\end{array}$ & $\begin{array}{c}\mathrm{CT}(\% \mathrm{DM}) \text { in second } \\
\text { highest plant }\end{array}$ \\
\hline $\mathrm{pBC2}-\mathrm{HACla}$ & 12 & 0.88 & 1.09 & 1.06 \\
\hline $\mathrm{pBC2}-\mathrm{HAC2a}$ & 15 & 0.91 & 1.52 & 1.36 \\
\hline $\mathrm{pT2}-\mathrm{HACa}$ & 40 & 1.24 & 2.23 & 1.99 \\
\hline pT2-HACb & 15 & 1.06 & 1.51 & 1.43 \\
\hline
\end{tabular}

Supplemental Table S2. M ean and highest quantity of soluble CTs produced in the leaves by T1 (A), BC2 and T2 (B) progeny. CTs are expressed relative to epigallocatechin equivalents and as a percentage of leaf dry matter (DM ). Values represent data averaged across two harvest dates, with two technical replicates per extraction. 


\begin{tabular}{|c|c|c|c|}
\hline \begin{tabular}{c} 
Generation \\
\hline T0
\end{tabular} & Sample origin* & Plant ID & $\begin{array}{c}\text { Soluble CTS } \\
\text { (\% DM) }\end{array}$ \\
\hline T1 $x$ & TO(3320) & TO(3320) & 0.61 \\
\hline T1 & pT1-HAC2* & GC18-33 & 0 \\
\hline T1 & T1-HACla & T1-HACla & 1.71 \\
\hline T2 & T1-HAC2a & T1-HAC2a & 1.52 \\
\hline T2 & pT2-HACa* & GC90-11 & 2.23 \\
\hline BC2 & pT2-HACa* & GC90-17 & 1.99 \\
\hline BC2 & pBC2-HACla* & BC2-11 & 1.09 \\
\hline
\end{tabular}

Supplemental Table S3. Quantity of soluble CTs in white clover leaf samples used for LC-MS analysis in Figures $7 \& 8$ and Supplemental Figure S4. CTs are expressed relative to epigallocatechin equivalents and as a percentage of leaf dry matter (DM ). See Figure 2A for the position of the plants and progeny in the crossing scheme.

*Indicates a progeny name, the rest are individual plants.

$\times$ Control sample. 